REVIEW

\title{
Prevalence Rate of Diabetes and Hypertension in Disaster-Exposed Populations: A Systematic Review and Meta-Analysis
}

\author{
Farzad Gohardehi ${ }^{1}$, Hesam Seyedin ${ }^{1 *}$, Shandiz Moslehi ${ }^{2}$
}

\footnotetext{
OPEN ACCESS

Citation: Farzad Gohardehi, Hesam Seyedin, Shandiz Moslehi. Prevalence Rate of Diabetes and Hypertension in Disaster-Exposed Populations: A Systematic Review and Meta-Analysis. Ethiop J Health Sci. 2020;30(3):439.doi:http://dx.doi.org/10.431 4/ejhs.v30 i3.15

Received: December 15, 2019

Accepted: December 31, 2019

Published: May 1, 2020

Copyright: (C2020 Farzad G., et al. This is an open access article distributed under the terms of the Creative Commons Attribution License, which permits unrestricted use, distribution, and reproduction in any medium, provided the original author and source are credited. Funding: Deputy of Research and Technology, Iran University of Medical Sciences, Tehran, Iran

Competing Interests: The authors declare that this manuscript was approved by all authors in its form and that no competing interest exists.

Affiliation and Correspondence: ${ }^{1}$ Department of Health in Disasters and Emergencies, School of Health Management and Information Sciences, Iran University of Medical Sciences, Tehran, Iran ${ }^{2}$ Department of Health in Disasters and Emergencies, Health Management and Economics Research Center, School of Health Management and Information Sciences, Iran University of Medical Sciences, Tehran, Iran *Email: h.seyedin@iums.ac.ir
}

\begin{abstract}
BACKGROUND: Non-communicable diseases (NCD) such as hypertension (HTN) and diabetes mellitus (DM) have been one of the major health problems in the world. The aim of this study was to evaluate the prevalence rate of DM and HTN following natural and man-made disasters that impose significant economic and psychological burdens on human communities.

METHODS: In this systematic and meta-analysis review, all crosssectional studies that at least one of their objectives was to measure the prevalence of HTN or DM in individuals affected by natural and man-made disasters were included. Literature review was done in international databases including PubMed, Scopus and Web of Science, from database inception to February 17, 2019. The extracted data included the bibliographic characteristics of the article, the age of the participants, number of participants, gender, sample size, outcome, duration of the follow-up, and prevalence of DM and HTN. Data were analyzed by STATA software (version 11) and random effect method and the $I 2$ index were used to investigate heterogeneity between the articles.

RESULTS: A total of 16 articles met the inclusion criteria. Based on the quality assessment, 11 papers were categorized as moderate and 5 paper were categorized as high quality. The prevalence of HTN and DM in disaster-exposed populations were 47.35 (CI 95\%: 38.53-56.17) and 13.56 (CI 95\%: 10.12-17.01), respectively.

CONCLUSION: The results of this study show a high prevalence of HTN and DM in survivors of major disasters, which is higher in comparison to the general population

KEYWORDS: Diabetes Mellitus; Hypertension; Disasters; Natural Disasters; Patient Care Management
\end{abstract}

\section{INTRODUCTION}

At the end of the 21 st century, the occurrence of natural disasters throughout the world increased six-fold comparing the last 50 years (1). Readiness regarding these disasters is generally related to how to evacuate disaster-stricken people from the site of disaster, how to provide transportation, food, water and shelter, and also how to prevent contagious diseases in the population who continue to live

DOI: http://dx.doi.org/10.4314/ejhs.v30i3.15 
following disaster (2-3). The mentioned factors are absolutely necessary, but they are not sufficient. In the case of unexpected disasters, preparedness is necessity in order to take care of a healthy population whose health is at risk, as well as those who are more vulnerable to stress compared to healthy people. Populations affected by major disasters can bear an onerous burden of disability and chronic diseases such as heart disease, hypertension (HTN), cancer, stroke, diabetes mellitus (DM), and chronic lung diseases (4). Chronic diseases are aggravated due to conditions caused by natural disasters (lack of food, lack of drinking water, cold or heat, physical or psychological stress, exposure to infections, etc.). Natural disasters can also pose the risk of adverse health outcomes for individual's suffering from limited morbidity and pregnant women (5-7). Individuals from lower socioeconomic levels, those without health insurance, as well as those suffering from mental illnesses and disabilities experience higher morbidity and mortality both during and after natural disasters (8-9). Various reports show the relationship between acute mental stresses resulting from major calamities or war and the increased risk of death (10-12). Severe stresses can increase the risk of prevalence of cardiovascular diseases and other diseases such as DM (13-16). Non-communicable diseases (NCDs) such as DM, cardiovascular diseases, cancers and respiratory diseases are regarded as a significant worldwide burden as well as a major health challenge for different nations. Populations of the nations throughout the world are generally getting older, and this factor has led to a significant appearance regarding the effects of NCDs. According to the estimation of the World Health Organization (WHO), the total annual mortality rate due to NCDs will increase from 38 million in 2012 to 55 million in 2030 (17-19).

$\mathrm{DM}$ is a chronic disease characterized by hyperglycemia resulting from a deficiency in insulin secretion, reduction of sensitivity to insulin, or both (20-21). The reported prevalence rate regarding DM varies around the world. Various studies have estimated the number of people with DM worldwide from 451 million in 2017 to 592 million in 2035 (22-23). Type $1 \mathrm{DM}$ can occur at any age, but its highest incidence is at birth to age
14 (24). Genetic background is important in the development of type $1 \mathrm{DM}$, but it is not enough for its emergence. Environmental factors play an important role in transforming a brief autoimmunity into type $1 \mathrm{DM}$. Improvement of living standards and reduction of exposure to microorganisms are likely to result in rise of autoimmunity $(23,25)$. Type $2 \mathrm{DM}$ has a slow onset, and unlike type 1, its common symptoms lack any kind of acute metabolic disorder. In type 2 $\mathrm{DM}$, there is a long pre-diagnosis period that more than half of cases could be left unnoticed (23).

Hypertension (HTN) is not only recognized as a risk factor for cardiovascular disease (CVD), but also it is a health concern in societies (26). The number of individuals suffering from HTN in the global population is estimated to be over 1.5 billion individuals (26-28). Approximately, 7.6 million premature deaths happen due to HTN that accounts for about $13.5 \%$ of the total premature death rate (29). However, the proportion of HTN is increasing in developed countries (30). This growth is higher in many low-income and middle-income countries (31-34). Risk factors regarding HTN include age, low fitness, tobacco consumption, unhealthy diet, high salt intake, and mental stress (35-36). As far as we know, only one systematic review study (without meta-analysis) has addressed NCDs subsequent to the occurrence of a major disaster at time of Great East Japan Earthquake (37). Due to importance of the issue and lack of comprehensive review in this regard in the literature, the aim of this study was to present a systematic review and meta-analysis to evaluate the prevalence of DM and HTN following the occurrence of natural and man-made disasters that impose a lot of economic and psychological burdens on human societies.

\section{METHODS}

This systematic review and meta-analysis included all cross-sectional descriptive or analytical crosssectional studies that at least one of their aims was to measure the prevalence of HTN and/or DM in people affected by natural and man-made disasters. Furthermore, all studies or reports resulting from the baseline phase of the cohort studies whether published as separate papers or as papers attributed to cohort profile were included. In addition, if the social trials included at least one group of non-

DOI: http://dx.doi.org/10.4314/ejhs.v30i3.15 
patients affected by natural or man-made disasters and in baseline phase they showed at least one outbreak of HTN or DM, they were included in our study. All papers or reports resulting from case reports, case series as well as cross-sectional studies based on hospitals or clinics whose participants suffered from a specific disease were excluded from the study this study. Also, studies in which all subjects suffered from HTN or DM were excluded.

Type of participant: All of the preliminary studies in which disaster-exposed participants had reported at least one of the two diseases of HTN or DM were included in the current systematic review study. The participants in the initial study had no limitations regarding their age and sex, in other words, each of the initial studies that had examined at least one of the two sexes in each age group was included. Participants in the initial study of this systematic review had no restrictions considering their ethnicity or race, and if an initial study that had investigated the prevalence of HTN or DM in an ethnicity, it was also included in the study.

Literature search strategy: The search was limited to the English language and was made for articles related to the topic using the following search terms: (hypertension OR diabetes) and (disaster OR crisis). The search was made on the international databases including PubMed and Scopus, in the title /abstract field and on the Web of Science in the topic field, from database inception to February 17, 2019. The gray literature was not actively searched, because they usually do not portray the whole picture of the results and when fully published the results may change substantially.

Study selection: This phase of the study was conducted in three sections. First of all, duplicate studies were deleted. Second, the title and abstract of the remaining papers were independently investigated by the researchers based on the inclusion and exclusion criteria. Disagreements were resolved by discussion. Finally, the screened studies were selected based on the full text and independently by the researchers. Also, the reference list of included studies were searched again for additional relevant articles.

Data extraction and quality assessment: Data extraction was separately performed by the researchers and entered into the researcher-made checklist. The checklist includes the first author's name, country, year of publication, age of participants, number of participants, gender, sample size, outcome, follow-up duration in cohort studies and prevalence of diabetes and hypertension. Quality assessment of the included studies was carried out by strengthening the reporting of observational studies in epidemiology (STROBE) checklist. Based on this checklist, studies obtain a score ranging from 0 to 34 . In this review, studies were classified into 3 groups according to their obtained score as weak quality, ranging from 0 to 11 ; moderate quality, ranging from 12 to 22; and high quality, ranging from 23 to 34.

Statistical analysis: The collected data was analyzed by STATA software (version 11). $\mathrm{I}^{2}$ index was applied in order to investigate the heterogeneity among the papers. Due to the $\mathrm{I}^{2}$ index of more than $50 \%$, the random effect method was used to combine studies.

\section{RESULTS}

After conducting a comprehensive screening of the literature and reviewing the full text of the papers, finally a total of 16 papers were included in our systematic review and meta-analysis. The process of selecting studies in the PRISMA flowchart is described in Figure 1. 


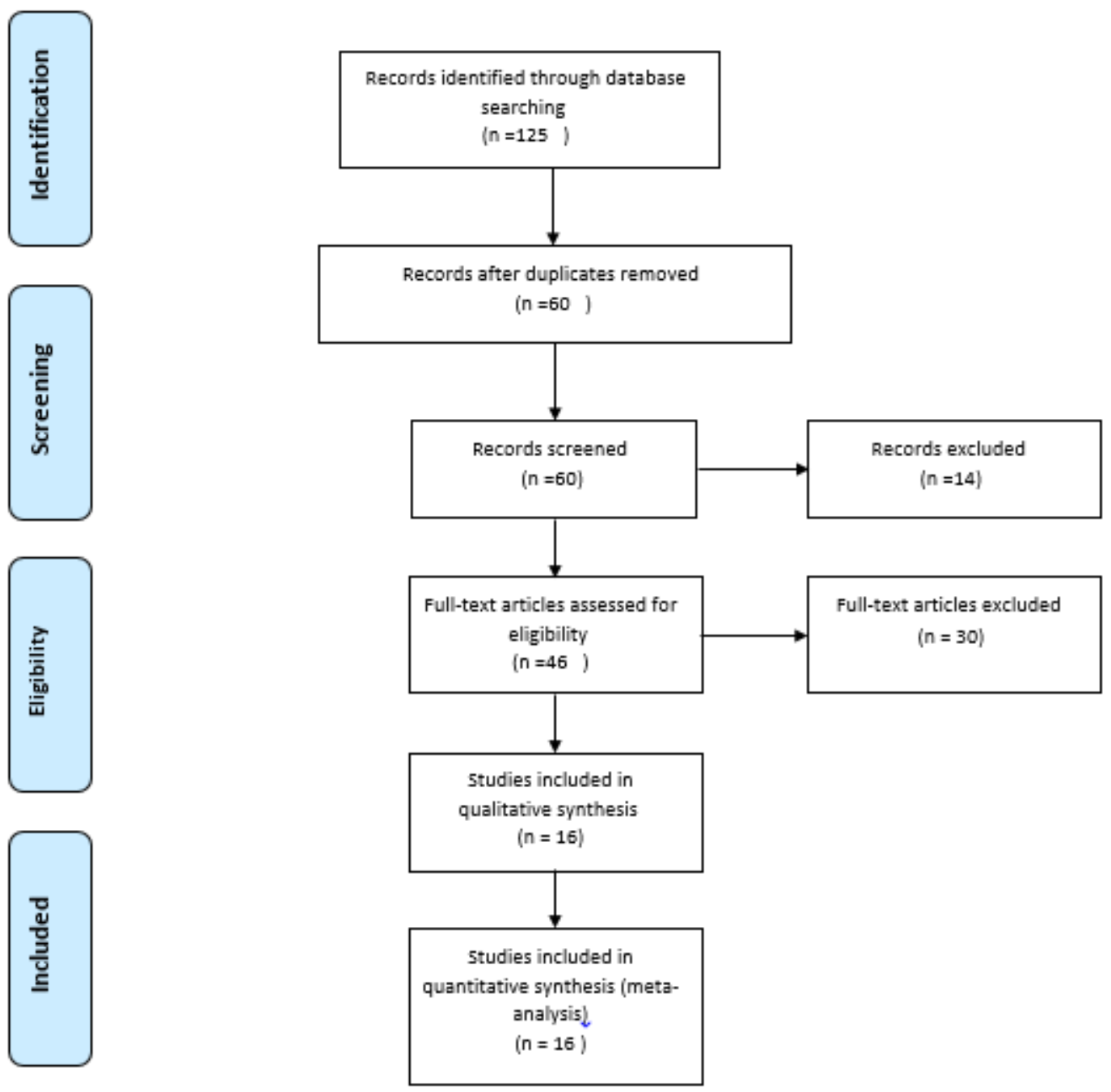

Figure 1: Flow diagram of literature search and retrieval

DOI: http://dx.doi.org/10.4314/ejhs.v30i3.15 
The design of most studies was cohort, and most of the included studies were conducted in USA and Japan. The Basic features of included studies are presented in Table 1.

Table 1: Summary of the basic features of included studies

\begin{tabular}{|c|c|c|c|c|c|c|c|c|}
\hline Authors & Year & Location & Study Design & Number of Participants & Gender (Female/Male) & Age (Mean) & Type of Disaster & F/U Duration \\
\hline Moscona et al. (38) & 2018 & USA & Cohort & 2341 & NR & NR & Hurricane & 12 \\
\hline Hayashi et al. (39) & 2017 & Japan & Cohort & 14492 & $7725 / 6767$ & 65.0 & Earthquake & 2.5 \\
\hline Slusky et al. (40) & 2017 & Israel & Cohort & 529 & NR & NR & Chernobyl Contamination & 4 \\
\hline Bello et al. (41) & 2017 & USA & Cohort & 10297 & NR & NR & Terrorist Attack & 3.5 \\
\hline Kuroda et al. (42) & 2017 & Japan & Cohort & 438 & $262 / 176$ & 73.6 & Earthquake & 3 \\
\hline Tanaka et al. (43) & 2016 & Japan & Cross-Sectional & 40 & $26 / 14$ & 69 & Earthquake & - \\
\hline Ebner et al. (44) & 2016 & Japan & Cohort & 576 & $329 / 247$ & $68.3 \pm 10.9$ & Nuclear power plant accident & 5 \\
\hline Nishizawa et al. (45) & 2015 & Japan & Cohort & 8 & $3 / 5$ & 76 & Earthquake & 1 \\
\hline Nakaya et al. (46) & 2015 & Japan & Cross-Sectional & 3032 & $1616 / 1516$ & NR & Earthquake & - \\
\hline Lin et al. (47) & 2015 & Taiwan & longitudinal survey & 288 & $199 / 96$ & 58.42 & Hurricane & 0.5 \\
\hline Miller-Archie et al. (48) & 2014 & USA & Cohort & 36899 & $14089 / 22810$ & NR & Terrorist Attack & NR \\
\hline Brackbill et al. (49) & 2014 & USA & Cohort & 2474 & $980 / 1494$ & NR & Terrorist Attack & NR \\
\hline Sun et al. (50) & 2013 & China & Cross-Sectional & 3230 & $2086 / 1144$ & 58 & Earthquake & - \\
\hline Jiao et al. (51) & 2012 & USA & Cohort & 418 & $121 / 297$ & $59 \pm 12$ & Hurrica & 5 \\
\hline Sharma et al. (52) & 2008 & USA & longitudinal survey & 3054 & $1619 / 1435$ & NR & Hurricane & - \\
\hline Dorn et al. (53) & 2006 & Netherlands & Cohort & 1462 & $768 / 694$ & NR & Fire disaster & 4 \\
\hline
\end{tabular}

$\mathrm{NR}=$ Non reported 
Quality assessment of studies: Based on the quality assessment performed using the STROBE checklist, 11 studies were categorized as moderate, and 5 studies were categorized as high level of quality.

Synthesis of results: The present study has combined the results reported in 13 and 11 studies to estimate the prevalence of HTN and DM. The result of combining HTN prevalence in the 13 studies was $47.35 \%$ (CI 95\%: 38.53-56.17), and the I-squared index related to heterogeneity in these studies was $99.8 \%$ (Figure 2). The result of combining DM prevalence in the 11 studies was

Study

ID

\begin{tabular}{|c|c|c|c|}
\hline Jiao (2012) & & + & $72.00(67.70,76.30)$ \\
\hline Sun (2013) & - & & $24.08(22.61,25.55)$ \\
\hline Miller-archie (2014) & - & & $38.32(37.82,38.82)$ \\
\hline Brackbill (2014) & $\bullet$ & & $36.30(34.41,38.19)$ \\
\hline Nakaya (2015) & $\bullet$ & & $33.21(31.53,34.89)$ \\
\hline $\operatorname{Lin}(2015)$ & & & $46.20(40.44,51.96)$ \\
\hline Tanaka (2016) & & $\longrightarrow$ & $70.00(55.80,84.20)$ \\
\hline Ebner (2016) & & + & $63.70(59.77,67.63)$ \\
\hline Slusky (2017) & + & & $34.21(30.17,38.25)$ \\
\hline Hayashi (2017) & & & $54.02(53.21,54.83)$ \\
\hline Bello (2017) & - & & $22.60(21.79,23.41)$ \\
\hline kuroda (2017) & + & & $44.50(39.85,49.15)$ \\
\hline Moscona (2018) & & - & $80.60(79.00,82.20)$ \\
\hline Overall (I-squared $=99.8 \%, p=0.000)$ & & & $47.35(38.53,56.17)$ \\
\hline NOTE: Weights are from random effects analysis & & & \\
\hline
\end{tabular}

Figure 2: The composition of hypertension prevalence in the reviewed studies

$\operatorname{ES}(95 \% \mathrm{CI})$
$13.56 \%$ (CI 95\%: 10.12-17.01), and the I-squared index for the combined studies was $99.5 \%$ (Figure 3). The result of combining HTN prevalence in the 5 studies conducted in the USA and the 5 ones conducted in Japan was 49.90\% (CI 95\%: 33.6466.16) and 52.31\% (CI 95\%: 40.14-64.47), respectively. The combination of DM prevalence in the 4 studies was done in the USA, and in the 4 ones was done in Japan, it was 20.53\% (CI 95\%: 10.18-30.89) and 10.57\% (CI 95\%: 8.23-12.90), respectively. 


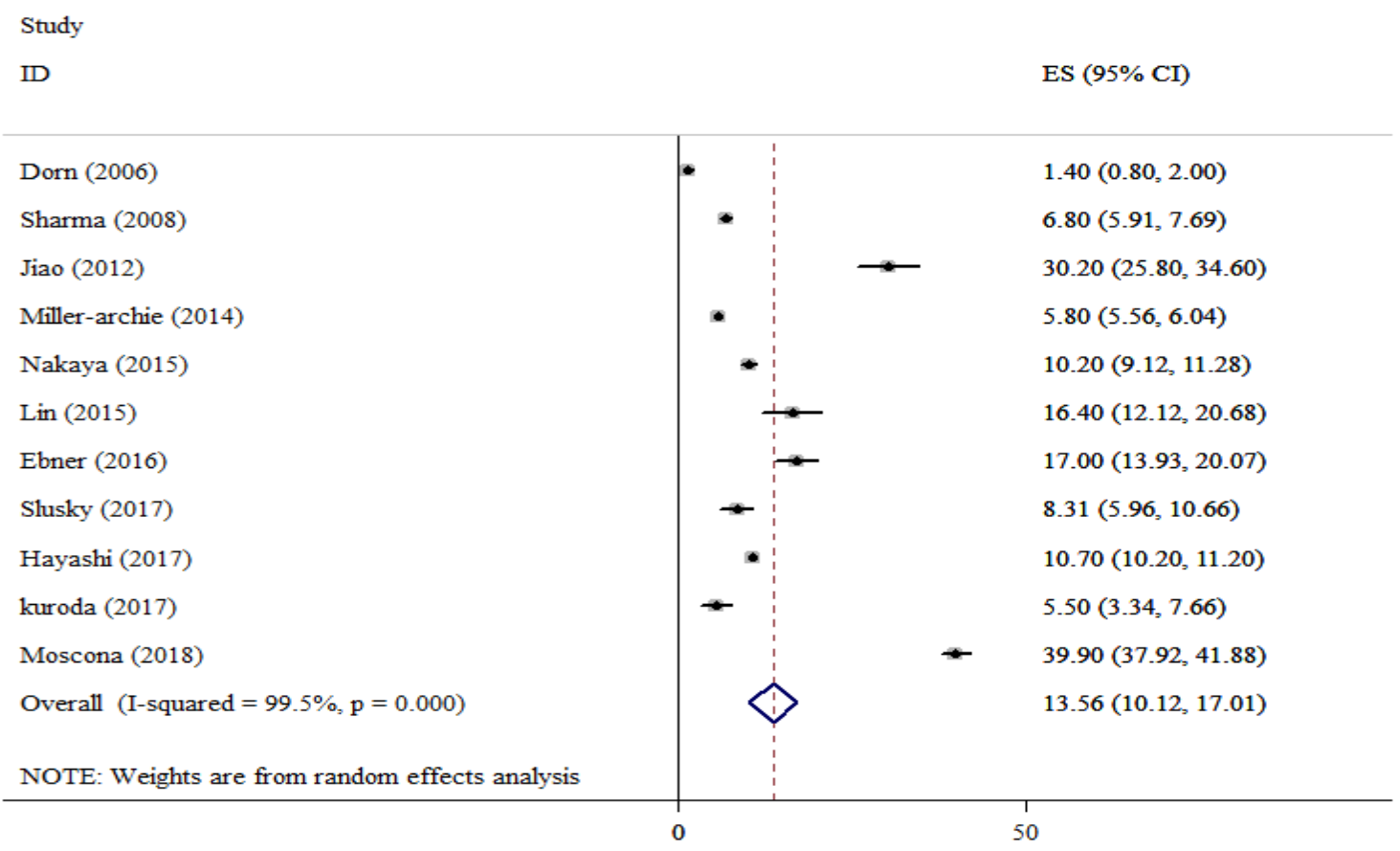

Figure 3: The composition of diabetes mellitus prevalence in the reviewed studies

\section{DISCUSSION}

As far as we know, the present study is the first systematic review study that has investigate the prevalence of DM and HTN in survivors of natural disasters. Our study was designed to examine the relationship between the prevalence of HTN and $\mathrm{DM}$ and the created conditions following natural or unnatural disasters that affect the human population. In general, HTN and DM are considered as common NCDs and impose huge economic and social burdens on different communities. During the occurrence of disasters, the primary focus of the responsible organs is usually on organizing settlements and ultimately preventing communicable diseases in survivors; therefore, chronic diseases such as HTN and DM are often overlooked. The results of our study showed a high prevalence of HTN and DM in survivors of disasters such as earthquakes, storms and major terrorist events such as the world trade towers incident that affected many individuals. This high prevalence may indicate a correlation between the mental and physical state of survivors and chronic diseases such as HTN and DM. During the occurrence of disasters, due to various factors such as unavailability of medicines, loss of medical records, disruption of mobility due to destruction of major paths to access treatment centers the controlled cases of HTN and DM may recur, and/or individuals who are in pre-hypertension and prediabetic stages may develop more advanced stages of these diseases, which can also contribute to an increase in these diseases prevalence in surviving population from disasters. In a study conducted by Murakami et al., similar results like ours were noted $(37,54)$, suggesting that HTN and DM prevalence was higher in survivors of the natural disaster compared to the general population. Also, in a study by Fonesca et al. It has been shown that after Hurricane Katrina, mean systolic blood pressure, hemoglobin A1c and low-density lipoprotein (LDL) cholesterol levels of diabetic patients have been significantly increased (55). Additionally, in a study that examined DM in individuals with post-traumatic stress disorder (PTSD) (16), high prevalence of DM was seen in individuals affected due to high mental stresses that led to PTSD. Other studies have also shown a correlation between the incidence of metabolic

DOI: http://dx.doi.org/10.4314/ejhs.v30i3.15 
syndrome and PTSD (56-57). Considering the results of this study and the high prevalence of DM and HTN in our study, the effect of psychological factors in the prevalence of these two diseases can be taken into account.

Due to the small number of identified studies, we did not assess the publication bias of included studies. Also, exclusion of non-English language papers and limiting the search of the literature to peer-reviewed journals were another limitations of this study.

In conclusion, this study found that the prevalence of HTN and DM was higher in survivors of disasters in comparison to the general population. Therefore, in addition to communicable diseases, some measurements should be taken to manage afflicted and susceptible individuals regarding HTN and DM and generally NCDs. Because these types of chronic diseases, impose a great burden on treatment system of the community.

\section{ACKNOWLEDGEMENTS}

This study is related to $\mathrm{PhD}$ dissertation approved and supported by the Iran University of Medical Sciences under number IUMS/SHMIS 1394/9211567211. The authors would like to forward special thanks to all participants for their cooperation in this study.

\section{REFERENCES}

1. Bronfman NC, Cisternas PC, Repetto PB, Castañeda JV. Natural disaster preparedness in a multi-hazard environment: Characterizing the sociodemographic profile of those better (worse) prepared. PLoS One. 2019; 14(4):e0214249.

2. Centers for Disease Control and Prevention (CDC). Hurricane Katrina response and guidance for health-care providers, relief workers, and shelter operators. MMWR Morb Mortal Wkly Rep. 2005; 54(35):877.

3. Toole MJ, Waldman RJ. The public health aspects of complex emergencies and refugee situations. Annu Rev Public Health. 1997; 18:283-312.

4. Miller AC, Arquilla B. Chronic diseases and natural hazards: impact of disasters on diabetic, renal, and cardiac patients. Prehosp Disaster Med. 2008; 23(2):185-94.

5. Bierman AS, Clancy CM. Health disparities among older women: identifying opportunities to improve quality of care and functional health outcomes. J Am Med Womens Assoc. 2001; 56(4):155-9, 188.

6. Menotti A, Mulder I, Nissinen A, Giampaoli S, Feskens EJ, Kromhout D. Prevalence of morbidity and multimorbidity in elderly male populations and their impact on 10-year all-cause mortality: The FINE study (Finland, Italy, Netherlands, Elderly). J Clin Epidemiol. 2001; 54(7):680-6.

7. Fernandez LS, Byard D, Lin C-C, Benson S, Barbera JA. Frail elderly as disaster victims: emergency management strategies. Prehosp Disaster Med. 2002; 17(2):67-74.

8. Morrow BH. Identifying and mapping community vulnerability. Disasters. 1999; 23(1):1-18.

9. Cordero JF. The epidemiology of disasters and adverse reproductive outcomes: lessons learned. Environ Health Perspect. 1993; 101 Suppl 2:1316.

10. Leor J, Poole WK, Kloner RA. Sudden cardiac death triggered by an earthquake. $N$ Engl $J$ Med. 1996; 334(7):413-9.

11. Trichopoulos D, Zavitsanos X, Katsouyanni K, Tzonou A, Dalla-Vorgia P. Psychological stress and fatal heart attack: the Athens (1981) earthquake natural experiment. Lancet. 1983; 321(8322):441-4.

12. Ogawa K, Tsuji I, Shiono K, Hisamichi S. Increased acute myocardial infarction mortality following the 1995 Great Hanshin-Awaji earthquake in Japan. Int $J$ Epidemiol. 2000; 29(3):449-55.

13. Schwartz B, French W, Mayeda G, Burstein S, Economides $\mathrm{C}$, Bhandari A, et al. Emotional stressors trigger cardiovascular events. Int $J$ Clin Pract. 2012; 66(7):631-9.

14. Sato M, Fujita S, Saito A, Ikeda Y, Kitazawa H, Takahashi $M$, et al. Increased incidence of transient left ventricular apical ballooning (socalled 'Takotsubo' cardiomyopathy) after the midNiigata Prefecture earthquake. Circ J. 2006; 70(8):947-53.

15. Aoki T, Fukumoto Y, Yasuda S, Sakata Y, Ito K, Takahashi J, et al. The great East Japan earthquake disaster and cardiovascular diseases. Eur Heart $J$. 2012; 33(22):2796-803.

16. Vancampfort D, Rosenbaum S, Ward PB, Steel Z, Lederman O, Lamwaka AV, et al. Type 2 diabetes among people with posttraumatic stress disorder: systematic review and meta-analysis. Psychosom Med. 2016; 78(4):465-73.

17. World Health Organization. Global action plan for the prevention and control of noncommunicable diseases 2013-2020 [September 1, 2017]. 
Available from: http://www.who.int/nmh/events/ncd_action_plan/e $\mathrm{n} /$.

18. World Health Organization. Global status report on noncommunicable disease 2014 [September 1, 2017]. Available from: http://www.who.int/nmh/publications/ncd-statusreport-2014/en/

19. Noncommunicable diseases. World Health Organization website [December 15, 2016]. Available from: http://www.who.int/mediacentre/factsheets/fs355/e $\mathrm{n} /$

20. Borgnakke WS, Ylöstalo PV, Taylor GW, Genco RJ. Effect of periodontal disease on diabetes: systematic review of epidemiologic observational evidence. J Periodontol. 2013; 84(4 Suppl):S13552.

21. Baradari AG, Emami Zeydi A, Aarabi M, Ghafari R. Metformin as an adjunct to insulin for glycemic control in patients with type 2 diabetes after CABG surgery: a randomized double blind clinical trial. Pak J Biol Sci. 2011; 14(23):1047-54.

22. Cho N, Shaw J, Karuranga S, Huang Y, da Rocha Fernandes J, Ohlrogge A, et al. IDF Diabetes Atlas: Global estimates of diabetes prevalence for 2017 and projections for 2045. Diabetes Res Clin Pract. 2018; 138:271-281.

23. Darvishi-Khezri H, Alipour A, Emami Zeydi A, Firouzian A, Mahmudi G, Omrani-Nava M. Is type 2 diabetes mellitus in mechanically ventilated adult trauma patients potentially related to the occurrence of ventilator-associated pneumonia? $J$ Res Med Sci. 2016; 21:19.

24. Blair M. Diabetes Mellitus Review. Urol Nurs. 2016; 36(1):27-36.

25. Hyppönen E, Läärä E, Reunanen A, Järvelin $M-R$, Virtanen SM. Intake of vitamin D and risk of type 1 diabetes: a birth-cohort study. Lancet. 2001; 358(9292):1500-3.

26. Kearney PM, Whelton M, Reynolds K, Muntner P, Whelton PK, He J. Global burden of hypertension: analysis of worldwide data. Lancet. 2005; 365(9455):217-23.

27. Danaei G, Finucane MM, Lin JK, Singh GM, Paciorek CJ, Cowan MJ, et al. National, regional, and global trends in systolic blood pressure since 1980: systematic analysis of health examination surveys and epidemiological studies with 786 country-years and 5. 4 million participants. Lancet. 2011; 377(9765):568-77.

28. Musa B, Galadanci N, Coker M, Bussell S, Aliyu $\mathrm{M}$. The global burden of pulmonary hypertension in sickle cell disease: a systematic review and meta-analysis. Ann Hematol. 2016; 95(11):175764.

29. Lawes CM, Vander Hoorn S, Rodgers A. Global burden of blood-pressure-related disease, 2001. Lancet. 2008; 371(9623):1513-8.

30. Olives C, Myerson R, Mokdad AH, Murray CJ, Lim SS. Prevalence, awareness, treatment, and control of hypertension in United States counties, 2001-2009. PLoS One. 2013; 8(4):e60308.

31. Saha A, Alleyne G. Recognizing noncommunicable diseases as a global health security threat. Bull World Health Organ. 2018; 96(11):792-793.

32. Franklin SS, Jacobs MJ, Wong ND, L'italien GJ, Lapuerta P. Predominance of isolated systolic hypertension among middle-aged and elderly US hypertensives: analysis based on National Health and Nutrition Examination Survey (NHANES) III. Hypertension. 2001; 37(3):869-74.

33. Grebla RC, Rodriguez CJ, Borrell LN, Pickering TG. Prevalence and determinants of isolated systolic hypertension among young adults: the 1999-2004 US National Health And Nutrition Examination Survey. J Hypertens. 2010; 28(1):1523.

34. McEniery CM, Yasmin, Wallace S, Maki-Petaja $\mathrm{K}$, McDonnell B, Sharman JE, et al. Increased stroke volume and aortic stiffness contribute to isolated systolic hypertension in young adults. Hypertension. 2005; 46(1):221.

35. Neupane D, McLachlan CS, Sharma R, Gyawali B, Khanal V, Mishra SR, et al. Prevalence of hypertension in member countries of South Asian Association for Regional Cooperation (SAARC): systematic review and meta-analysis. Medicine (Baltimore). 2014; 93(13):e74.

36. Paulus EJ, Argo TR, Egge JA. The impact of posttraumatic stress disorder on blood pressure and heart rate in a veteran population. $J$ Trauma Stress. 2013; 26(1):169-72.

37. Murakami A, Sasaki H, Pascapurnama DN, Egawa S. Noncommunicable diseases after the Great East Japan Earthquake: systematic review, 2011-2016. Disaster Med Public Health Prep. 2018; 12(3):396-407.

38. Moscona JC, Peters MN, Maini R, Katigbak P, Deere B, Gonzales H, et al. The incidence, risk factors, and chronobiology of acute myocardial infarction ten years after Hurricane Katrina. Disaster Med Public Health Prep. 2019; 13(2):217-222. 
39. Hayashi Y, Nagai M, Ohira T, Satoh H, Sakai A, Ohtsuru A, et al. The impact of evacuation on the incidence of chronic kidney disease after the Great East Japan Earthquake: The Fukushima Health Management Survey. Clin Exp Nephrol. 2017; 21(6):995-1002.

40. Slusky DA, Cwikel J, Quastel MR. Chronic diseases and mortality among immigrants to Israel from areas contaminated by the Chernobyl disaster: a follow-up study. Int $J$ Public Health. 2017; 62(4):463-469.

41. Bello GA, Teitelbaum SL, Lucchini RG, Dasaro CR, Shapiro M, Kaplan JR, et al. Assessment of cumulative health risk in the World Trade Center general responder cohort. Am J Ind Med. 2018; 61(1):63-76.

42. Kuroda Y, Iwasa H, Goto A, Yoshida K, Matsuda $\mathrm{K}$, Iwamitsu $\mathrm{Y}$, et al. Occurrence of depressive tendency and associated social factors among elderly persons forced by the Great East Japan Earthquake and nuclear disaster to live as longterm evacuees: a prospective cohort study. $B M J$ Open. 2017; 7(9):e014339.

43. Tanaka R, Okawa M, Ujike Y. Predictors of Hypertension in Survivors of the Great East Japan Earthquake, 2011: A Cross-sectional Study. Prehosp Disaster Med. 2016; 31(1):17.

44. Ebner DK, Ohsawa M, Igari K, Harada KH, Koizumi A. Lifestyle-related diseases following the evacuation after the Fukushima Daiichi nuclear power plant accident: a retrospective study of Kawauchi Village with long-term follow-up. BMJ Open. 2016; 6:e011641.

45. Nishizawa M, Hoshide S, Okawara Y, Shimpo M, Matsuo T, Kario K. Aftershock Triggers Augmented Pressor Effects in Survivors: FollowUp of the Great East Japan Earthquake. Am J Hypertens. 2015; 28(12):1405-8.

46. Nakaya N, Nakamura $\mathrm{T}$, Tsuchiya $\mathrm{N}$, Tsuji I, Hozawa A, Tomita H. The Association between Medical Treatment of Physical Diseases and Psychological Distress after the Great East Japan Earthquake: The Shichigahama Health Promotion Project. Disaster Med Public Health Prep. 2015; 9(4):374-81.

47. Lin CY, Chen TC, Dai CY, Yu ML, Lu PL, Yen $\mathrm{JH}$, et al. Serological investigation to identify risk factors for post-flood infectious diseases: a longitudinal survey among people displaced by Typhoon Morakot in Taiwan. BMJ Open. 2015; 5(5):e007008.
48. Miller-Archie SA, Jordan HT, Ruff RR, Chamany $\mathrm{S}$, Cone JE, Brackbill RM, et al. Posttraumatic stress disorder and new-onset diabetes among adult survivors of the World Trade Center disaster. Prev Med. 2014; 66:34-8.

49. Brackbill RM, Cone JE, Farfel MR, Stellman SD. Chronic Physical Health Consequences of Being Injured During the Terrorist Attacks on World Trade Center on September 11, 2001. Am J Epidemiol. 2014; 179(9):1076-85.

50. Sun XC, Zhou XF, Chen S, Liu YX, Wang YJ, Zhang $\mathrm{W}$, et al. Clinical characteristics of hypertension among victims in temporary shield district after Wenchuan earthquake in China. Eur Rev Med Pharmacol Sci. 2013; 17(7):912-6.

51. Jiao Z, Kakoulides SV, Moscona J, Whittier J, Srivastav S, Delafontaine P, et al. Effect of Hurricane Katrina on Incidence of Acute Myocardial Infarction in New Orleans Three Years After the Storm. Am J Cardiol. 2012; 109(4):5025 .

52. Sharma AJ, Weiss EC, Young SL, Stephens K, Ratard R, Straif-Bourgeois S, et al. Chronic disease and related conditions at emergency treatment facilities in the New Orleans area after Hurricane Katrina. Disaster Med Public Health Prep. 2008; 2(1):27-32.

53. Dorn T, Yzermans CJ, Guijt H, van der Zee J. Disaster-related stress as a prospective risk factor for hypertension in parents of adolescent fire victims. Am J Epidemiol. 2007; 165(4):410-7.

54. Tomio J, Sato H. Emergency and disaster preparedness for chronically ill patients: a review of recommendations. Open Access Emerg Med. 2014; 6:69-79.

55. Fonseca VA, Smith H, Kuhadiya N, Leger SM, Yau CL, Reynolds K, et al. Impact of a natural disaster on diabetes: exacerbation of disparities and long-term consequences. Diabetes Care. 2009; 32(9):1632-8.

56. Bartoli F, Carra G, Crocamo C, Carretta D, Clerici M. Metabolic syndrome in people suffering from posttraumatic stress disorder: a systematic review and meta-analysis. Metab Syndr Relat Disord. 2013; 11(5):301-8.

57. Rosenbaum S, Stubbs B, Ward PB, Steel Z, Lederman O, Vancampfort D. The prevalence and risk of metabolic syndrome and its components among people with posttraumatic stress disorder: a systematic review and meta-analysis. Metabolism. 2015; 64(8):926-33.

DOI: http://dx.doi.org/10.4314/ejhs.v30i3.15 